\title{
Decreased activity of plasma ADAMTS13 are related to enhanced cytokinemia and endotoxemia in patients with acute liver failure
}

\author{
HIROAKI TAKAYA $^{1}$, HITOSHI YOSHIJI ${ }^{1}$, HIDETO KAWARATANI ${ }^{1}$, KAZUYA SAKAI $^{2}$, \\ MASANORI MATSUMOTO $^{2}$, YOSHIHIRO FUJIMURA ${ }^{2}$ and HIROSHI FUKUI ${ }^{1}$ \\ ${ }^{1}$ Third Department of Internal Medicine; ${ }^{2}$ Department of Blood Transfusion Medicine, \\ Nara Medical University, Kashihara, Nara 634-8522, Japan
}

Received April 7, 2017; Accepted June 19, 2017

DOI: $10.3892 /$ br.2017.945

\begin{abstract}
Deficient ADAM metalloproteinase with thrombospondin type-1 motif, member 13 (ADAMTS13) activity (ADAMTS13:AC) results in the accumulation of unusually large von Willebrand factor multimers (UL-VWFM) and causes microcirculatory disturbances and multiple organ failure, while endotoxins trigger the activation of a coagulation cascade. The objective of the present study was to explore the role of ADAMTS13 in endotoxemia in patients with acute liver failure (ALF). Plasma concentrations of endotoxin and cytokines, including interleukin (IL)-6 and IL-8, and activity of the plasma ADAMTS13 inhibitor were determined, along with ADAMTS13:AC, the VWF antigen (VWF:Ag) and UL-VWFM, in 27 patients with acute hepatitis $(\mathrm{AH})$, 11 patients with ALF, and 10 healthy controls. IL- 6 and IL-8 concentrations on admission were significantly higher in patients with ALF than in those with AH or in healthy controls. ADAMTS13:AC concomitantly decreased and VWF:Ag progressively increased with increasing cytokine concentrations from the normal range to $>100 \mathrm{pg} / \mathrm{ml}$. The inhibitor was detected in 8 patients with $\mathrm{ALF}(0.6$ to $2.4 \mathrm{BU} / \mathrm{ml})$ and 6 patients with $\mathrm{AH}(0.6$ to $0.8 \mathrm{BU} / \mathrm{ml})$. Patients with the inhibitor reported lower ADAMTS13:AC, higher VWF:Ag and lower functional liver capacity than those without the inhibitor. Collectively, the findings suggested that decreased ADAMTS13:AC and increased VWF:Ag may be induced by pro-inflammatory cytokinemia as well as the presence of the ADAMTS13 inhibitor, both of which may be closely related to enhanced endotoxemia in patients with ALF.
\end{abstract}

Correspondence to: Dr Hiroaki Takaya, Third Department of Internal Medicine, Nara Medical University, 840 Shijo-cho, Kashihara, Nara 634-8522, Japan

E-mail: htky@naramed-u.ac.jp

Key words: acute liver failure, ADAMTS13, von Willebrand factor, cytokines, endotoxin

\section{Introduction}

ADAM metalloproteinase with thrombospondin type-1 motif, member 13 (ADAMTS13) is a zinc-containing enzyme specifically cleaving the multimeric von Willebrand factor (VWF) between Tyr1605 and Met1606 within the VWF A2 domain (1). ADAMTS13 is produced exclusively in hepatic stellate cells adjacent to endothelial cells (2). VWF is synthesized in vascular endothelial cells and released into plasma as 'unusually large' VWF multimers (UL-VWFM) (3). ADAMTS13 deficiency, caused by either ADAMTS13 gene mutations (4) or inhibitory autoantibodies against ADAMTS13 (5) increases UL-VWFM plasma levels, causing platelet clumping and thrombi under high shear stress, resulting in microcirculatory disturbances $(3,5)$. ADAMTS13 deficiency is linked to thrombotic thrombocytopenic purpura (TTP) occurrence (5) characterized by thrombocytopenia, renal dysfunction, fluctuating neurological symptoms, microangiopathic hemolytic anemia and fever (6).

The role of ADAMTS13 role in alcoholic hepatitis (7), liver cirrhosis (8) and acute liver failure (ALF) (9) progression is reported by studies, suggesting that ADAMTS13 enzyme-VWF substrate imbalances are related to liver disorders and multiple organ failure (MOF) progression.

Endotoxemia, due to Kupffer cell dysfunction and increased intestinal permeability, triggers pro-inflammatory cytokine production, possibly causing a systemic inflammatory response syndrome and microcirculatory disturbances, leading to MOF $(10,11)$ Recent in vitro studies demonstrated associations of inflammatory cytokines with decreased ADAMTS13 activity (ADAMTS13:AC) (12) and increased UL-VWFM release from endothelial cells (13). Inflammation-associated ADAMTS13 deficiency promotes UL-VWFM formation in patients with sepsis (14), indicating a close linkage between cytokinemia, endotoxemia and ADAMTS13:AC in ALF.

The authors explored the potential mechanisms underlying reduced plasma ADAMTS13:AC in ALF patients by determining plasma cytokine and endotoxin concentrations and evaluating ADAMTS13 inhibitor activity.

\section{Materials and methods}

Ethical approval. All procedures performed in studies involving human participants were in accordance with the 
ethical standards of the Institutional, National Research Committee and with the 1964 Helsinki Declaration. All subjects gave informed consent for participation. The study was approved by the Ethics Committee of Nara Medical University (Kashihara, Japan).

Patients. A total of 27 acute hepatitis (AH) patients (14 men, 13 women; mean age, 59.8 years) and 11 ALF patients ( 6 men, 5 women; mean age, 47.9 years; Table I) were enrolled and admitted to Nara Medical University between December 2001 and September 2009. None had a history of coagulopathies, sepsis or platelet disorders. ALF was diagnosed based on physical findings and laboratory tests according to the criteria of Intractable Hepato-Biliary Diseases Study Group of Japan (15). ALF was defined as prothrombin time values $40 \%$ or less of standardized values or international normalized ratios 1.5 or more caused by severe liver damage within 8 weeks of symptom onset. For the control group, 10 healthy volunteers aged 20-40 years were also analyzed.

ADAMTS13:AC, VWF antigen (VWF:Ag), UL-VWF, and ADAMTS13 inhibitor assays. Blood samples were collected from patients at admission into plastic tubes containing $1 / 10$ th volume of $3.8 \%$ sodium citrate (anticoagulant). Platelet-poor plasma was prepared by centrifuging plasma samples at $3,000 \mathrm{x} \mathrm{g}$ for $15 \mathrm{~min}$ at $4^{\circ} \mathrm{C}$; aliquots were stored at $-80^{\circ} \mathrm{C}$. Plasma ADAMTS13:AC was determined using a chromogenic ELISA (ADAMTS13-act-ELISA kit, cat. no. 019491; Kainos Laboratories Inc., Tokyo, Japan). The detection limit of the activity was $0.5 \%$; normal value was $99 \pm 22 \%$ (mean \pm standard deviation). Plasma UL-VWFM was analyzed by $0.9 \%$ SDS-agarose gel electrophoresis using $1 \mu \mathrm{l}$ sample aliquots (16). High-molecular-weight bands undetected in normal plasma were defined as UL-VWFM (17). Plasma VWF:Ag was measured by sandwich ELISA using a rabbit polyclonal anti-human VWF antibody (1:1,000; cat. no. A0082; Dako; Agilent Technologies, Inc., Santa Clara, CA, USA). ADAMTS13 inhibitor activity was measured using heat-inactivated plasma (at $56^{\circ} \mathrm{C}$ for $30 \mathrm{~min}$ ). One Bethesda's unit (BU) of inhibitor was defined as the amount required to reduce ADAMTS13:AC to 50\% of control values (18); its titer was estimated to be significant at $>0.5 \mathrm{BU} / \mathrm{ml}$.

Cytokine concentrations. Interleukin (IL)-6 and IL-8 plasma concentrations were determined using immunoassay kits (cat. no. of IL-6, KHC0061; cat. no. of IL-8, KHC0081; BioSource International; Thermo Fisher Scientific, Inc., Waltham, MA, USA). The detection limits of IL- 6 and IL- 8 plasma levels are below $7.8 \mathrm{pg} / \mathrm{ml}$ and $15.6 \mathrm{pg} / \mathrm{ml}$, respectively. AH or ALF patients were classified into three groups according to IL-6 plasma level (8): i) $<7.8 \mathrm{pg} / \mathrm{ml}$; ii) $7.8-100 \mathrm{pg} / \mathrm{ml}$; and iii) $>100 \mathrm{pg} / \mathrm{ml}$. Patients were also classified into two groups according to IL-8 plasma level: i) $<15.6 \mathrm{pg} / \mathrm{ml}$ and ii) $\geq 15.6 \mathrm{pg} / \mathrm{ml}$ (7).

Endotoxin determination. Blood specimens from 10 healthy controls and AH or ALF patients were obtained under aseptic conditions by peripheral venipuncture using pyrogen-free syringes and needles and were mixed in pyrogen-free tubes containing $1 / 10$ th volume of $3.8 \%$ sodium citrate (anticoagulant). Plasma was immediately separated in a refrigerated centrifuge at $3,000 \mathrm{x}$ g for $15 \mathrm{~min}$ at $4^{\circ} \mathrm{C}$ and stored at $-80^{\circ} \mathrm{C}$ for further analysis. Endotoxin activity was measured using a chromogenic substrate assay (Toxicolor LS-M Set; Seikagaku Kogyo Co., Ltd., Tokyo, Japan) with kinetic analysis (19). Briefly, $50 \mu 1$ plasma sample was mixed with $450 \mu 10.02 \%$ Triton X-100, and heated at $70^{\circ} \mathrm{C}$ for $10 \mathrm{~min}$ to inactivate any inhibitor reacting with endotoxin; serial standard solutions were prepared to final exogenous endotoxin concentrations $(180,90,45,22.5,11.3$ and $5.6 \mathrm{pg} / \mathrm{ml}$ ). Absorbance was measured at $37^{\circ} \mathrm{C}$ every $15 \mathrm{sec}$ for $30 \mathrm{~min}$ by a microprocessor-controlled reader (Wellreader, SK603; Seikagaku Kogyo Co., Ltd.). The linear part of the kinetics curve was read, and endogenous plasma endotoxin concentrations were calculated from the obtained standard curve. Determinations were performed in duplicate and mean values were utilized.

Statistical analysis. Differences between paired and unpaired groups were analyzed using the Mann-Whitney U-test and the Steel-Dwass test after the hypothesis in analysis of variance was rejected. Correlations were calculated using the Spearman rank test. Categorical data were analyzed using the Fisher's exact test. Analyses were performed using EZR (version 1.35; Saitama Medical Center, Jichi Medical University, Saitama, Japan), a graphical user interface for $\mathrm{R}$ (version 2.13.0; The R Foundation for Statistical Computing, Vienna, Austria) (20). Data are expressed as means \pm standard deviation. A two-tailed $\mathrm{P}<0.05$ was considered to indicate a statistically significant difference.

\section{Results}

Clinical characteristics and laboratory values. Clinical data from AH and ALF patients are presented in Table I. Serum total bilirubin, aspartate aminotransferase, alanine aminotransferase, lactate dehydrogenase, blood urea nitrogen, creatinine and white blood cell counts were higher in ALF patients than in AH patients, whereas serum albumin, prothrombin time, and platelet count were lower in ALF patients than in AH patients. All AH patients survived, while 9 of 11 ALF patients died of hepatic failure within 12-132 days of admission. In ALF patients, various causes were implicated, including the hepatitis B virus (2 patients), autoimmune hepatitis (1 patient), drugs ( 2 patients) and systemic circulatory disturbances ( 2 patients); in 4 patients, the cause was cryptogenic or unknown. ALF type was considered to be acute in 6 patients, subacute in 4 , and late-onset hepatic failure in 1 . The 9 non-survivors with ALF showed grade II-III hepatic encephalopathy, while 3 had ascites, 3 had heart failure and 4 had sepsis, indicating MOF occurrence. Only 5 of these patients had disseminated intravascular coagulation (DIC). Of the remaining 2 survivors with ALF, one was complicated by hepatic encephalopathy, ascites and DIC but not by heart failure or sepsis, while the other had moderate ascites and required treatment with a liver transplant. A total of 9 ALF patients was treated with plasma exchange and standard therapy. Two patients did not receive plasma exchange because of systemic circulatory disturbances and were treated with liver transplantation.

Plasma ADAMTS13:AC, VWF:Ag, and UL-VWFM. Plasma ADAMTS13:AC on admission was significantly lower in 
Table I. Clinical data of patients with acute hepatitis and acute liver failure.

\begin{tabular}{|c|c|c|c|}
\hline Variable & Acute hepatitis $(n=27)$ & Acute liver failure $(n=11)$ & P-value \\
\hline Age (years) & $47.9 \pm 19.1$ & $59.8 \pm 18.0$ & NS \\
\hline Sex (male/female) & $14 / 13$ & $6 / 5$ & NS \\
\hline Serum total bilirubin (mg/dl) & $6.3 \pm 7.0$ & $11.0 \pm 7.1$ & $\mathrm{P}<0.05$ \\
\hline Aspartate aminotransferase (IU/l) & $515.8 \pm 520.8$ & $2,253.1 \pm 2,572.4$ & $\mathrm{P}<0.05$ \\
\hline Alanine aminotransferase (IU/l) & $717.1 \pm 856.4$ & $1,642.6 \pm 1,515.7$ & $\mathrm{P}<0.05$ \\
\hline Lactate dehydrogenase (IU/l) & $824.7 \pm 1,784.9$ & $3,490.7 \pm 5,212.4$ & $\mathrm{P}<0.05$ \\
\hline alkaline phosphatase (IU/l) & $499.6 \pm 630.0$ & $1,093.3 \pm 1,693.5$ & NS \\
\hline$\gamma$-glutamyl transpeptidase (IU/l) & $213.7 \pm 261.1$ & $106.9 \pm 82.8$ & NS \\
\hline Cholinesterase (IU/1) & $234.1 \pm 80.1$ & $149.0 \pm 55.8$ & NS \\
\hline Serum albumin (g/dl) & $3.7 \pm 0.7$ & $3.4 \pm 0.9$ & $\mathrm{P}<0.05$ \\
\hline Blood urea nitrogen (mg/dl) & $13.2 \pm 12.1$ & $43.0 \pm 38.9$ & $\mathrm{P}<0.05$ \\
\hline Serum creatinine $(\mathrm{mg} / \mathrm{dl})$ & $0.8 \pm 0.5$ & $1.7 \pm 1.2$ & $\mathrm{P}<0.05$ \\
\hline Prothrombin time $(\%)$ & $86.6 \pm 24.8$ & $35.5 \pm 21.9$ & $\mathrm{P}<0.05$ \\
\hline Fibrin/fibrinogen degradation products $(\mu \mathrm{g} / \mathrm{ml})$ & $29.1 \pm 23.5$ & $3.5 \pm 2.5$ & $\mathrm{P}<0.05$ \\
\hline White blood cell count $\left(/ \mathrm{mm}^{3}\right)$ & $6,018.3 \pm 2,575.4$ & $11,444.4 \pm 5,789.0$ & $\mathrm{P}<0.05$ \\
\hline Hemoglobin $(\mathrm{g} / \mathrm{dl})$ & $12.7 \pm 2.2$ & $11.2 \pm 1.9$ & NS \\
\hline Platelet count $\left(\times 10^{4} / \mathrm{mm}^{3}\right)$ & $22.0 \pm 9.0$ & $10.9 \pm 11.4$ & $\mathrm{P}<0.05$ \\
\hline Hepatic encephalopathy (grade II-III) & 0 & 11 & $\mathrm{P}<0.05$ \\
\hline Renal failure/heart failure/ascites/sepsis/DIC & $0 / 0 / 0 / 0 / 1$ & $4 / 3 / 4 / 4 / 6$ & \\
\hline UL-VWFM positive & 0 & 4 & $\mathrm{P}<0.05$ \\
\hline Outcome (alive/dead) & $27 / 0$ & $2 / 9$ & $\mathrm{P}<0.05$ \\
\hline
\end{tabular}

Data are expressed as means \pm standard deviation. NS, not significant; UL-VWFM, unusually large von Willebrand factor multimers; DIC, disseminated intravascular coagulation.

AH $(63.9 \pm 14.5 \% ; \mathrm{P}<0.05)$ and ALF $(14.4 \pm 8.6 \% ; \mathrm{P}<0.05)$ patients than in healthy subjects $(126.6 \pm 15.0 \%)$. Activity further decreased in ALF patients compared with $\mathrm{AH}$ patients $(\mathrm{P}<0.05$; Fig. 1A). Values of plasma VWF:Ag were higher in AH $(231.4 \pm 90.6 \% ; \mathrm{P}<0.05)$ and ALF $(535.2 \pm 238.9 \% ; \mathrm{P}<0.05)$ patients than in healthy subjects $(108.8 \pm 76.6 \%)$ VWF:Ag values were higher in ALF patients than in $\mathrm{AH}$ patients $(\mathrm{P}<0.05$; Fig. 1B). Plasma UL-VWFM (Fig. 2) was detected in 5 (13.2\%) of $38 \mathrm{AH}$ and ALF patients. Plasma ADAMTS13:AC values of patients with UL-VWFM $(10.9 \pm 10.3 \%)$ were significantly lower than values of those without UL-VWFM $(59.1 \pm 34.5 \%$; $\mathrm{P}<0.05$; Fig. 3A). Plasma VWF:Ag values of patients with UL-VWFM (877.2 $\pm 291.4 \%)$ were significantly higher than values of those without $(280.6 \pm 34.7 \%$; P<0.05; Fig. 3B). Plasma ADAMTS13:AC values on admission $(53.9 \pm 34.6 \%$ vs. $24.1 \pm 16.8 \%$; $\mathrm{P}<0.05)$ were higher in survivors than in non-survivors, respectively. Plasma VWF:Ag values on admission $(252.8 \pm 127.4 \%$ vs. $419.6 \pm 99.5 \%$; $\mathrm{P}<0.05)$ were lower in survivors than in non-survivors, respectively (Table II).

Plasma cytokine levels and their relationship to ADAMTS13:AC, VWF:Ag, and UL-VWFM. Plasma IL-6 concentrations at admission in ALF patients $(648.6 \pm 460.7 \mathrm{pg} / \mathrm{ml})$ were significantly higher than those in healthy controls $(<7.8 \mathrm{pg} / \mathrm{ml} ; \mathrm{P}<0.05)$ or those in AH patients $(15.4 \pm 14.0 \mathrm{pg} / \mathrm{ml} ; \mathrm{P}<0.05)$. However, plasma IL-6 levels did not differ between AH patients and healthy subjects (Fig. 1C). Plasma IL-8 concentrations were significantly higher in ALF patients $(83.8 \pm 98.2 \mathrm{pg} / \mathrm{ml})$ than in $\mathrm{AH}$ patients $(18.0 \pm 23.9 \mathrm{pg} / \mathrm{ml} ; \mathrm{P}<0.05)$. However, IL-8 concentrations did not differ between AH patients and healthy subjects (Fig. 1D). ADAMTS13:AC on admission concomitantly decreased along with the elevation of plasma IL-6 levels ( $\mathrm{P}<0.05$; Fig. 4A). Plasma ADAMTS13:AC levels in patients with IL-8 concentrations $\geq 15.6 \mathrm{pg} / \mathrm{ml}$ were significantly lower than those in patients with IL- 8 concentrations $<15.6 \mathrm{pg} / \mathrm{ml}$ ( $\mathrm{P}<0.05$; Fig. $4 \mathrm{~B})$. VWF:Ag on admission increased with increasing IL-6 levels $(\mathrm{P}<0.05$; Fig. 4C). In patients with IL-8 levels $\geq 15.6 \mathrm{pg} / \mathrm{ml}$, VWF:Ag was significantly higher than in those with IL-8 levels $<15.6 \mathrm{pg} / \mathrm{ml}$ (Fig. 4D). Plasma IL-6 levels of patients with UL-VWFM $(739.0 \pm 291.9 \mathrm{pg} / \mathrm{ml})$ were significantly higher than levels of those without $(116.0 \pm 54.9 \mathrm{pg} / \mathrm{ml} ; \mathrm{P}<0.05$; (Fig. 3C). Plasma IL-8 levels of patients with UL-VWFM $(123.2 \pm 61.0 \mathrm{pg} / \mathrm{ml})$ were significantly higher than levels of those without $(32.0 \pm 7.7 \mathrm{pg} / \mathrm{ml} ; \mathrm{P}<0.05$; Fig. 3D).

Plasma endotoxin levels and their relationships to ADAMTS13:AC and VWF:Ag. Plasma endotoxin levels in normal subjects were $<10 \mathrm{pg} / \mathrm{ml}$ (average, $7.9 \pm 1.7 \mathrm{pg} / \mathrm{ml}$ ). Plasma endotoxin concentration on admission was significantly higher in ALF patients $(22.9 \pm 12.7 \mathrm{pg} / \mathrm{ml})$ than in $\mathrm{AH}$ patients $(8.0 \pm 4.2 \mathrm{pg} / \mathrm{ml}$; $\mathrm{P}<0.05$; Fig. 5A). Plasma ADAMTS13:AC levels were significantly lower in patients with endotoxin levels $\geq 20 \mathrm{pg} / \mathrm{ml}(18.5 \pm 6.9 \%)$ than in those with lower endotoxin levels $(34.8 \pm 14.6 \%$; $\mathrm{P}<0.05$; Fig. $5 \mathrm{~B})$. Plasma levels of VWF:Ag were significantly higher in patients with endotoxin 
A

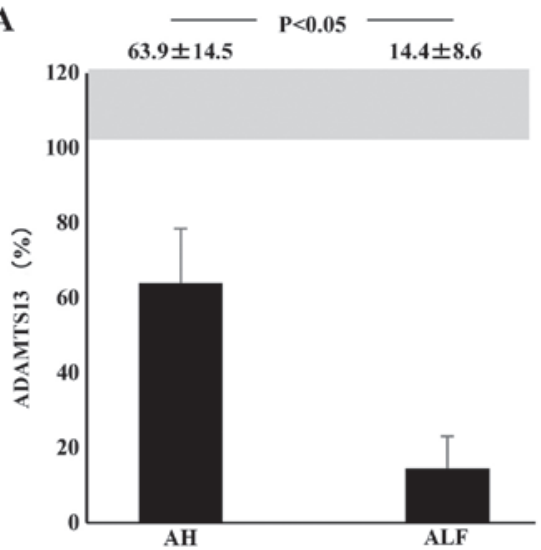

C

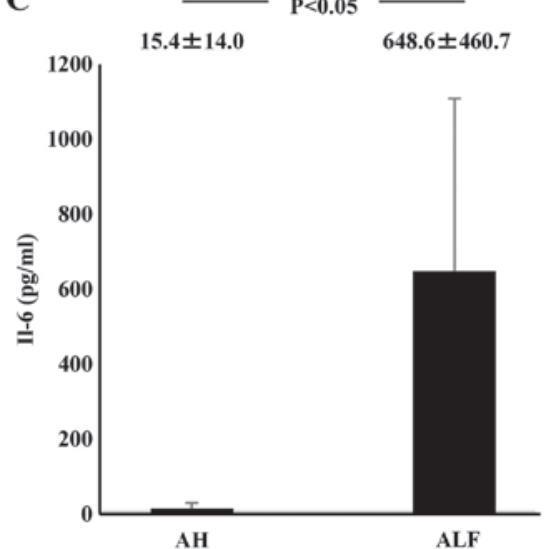

B

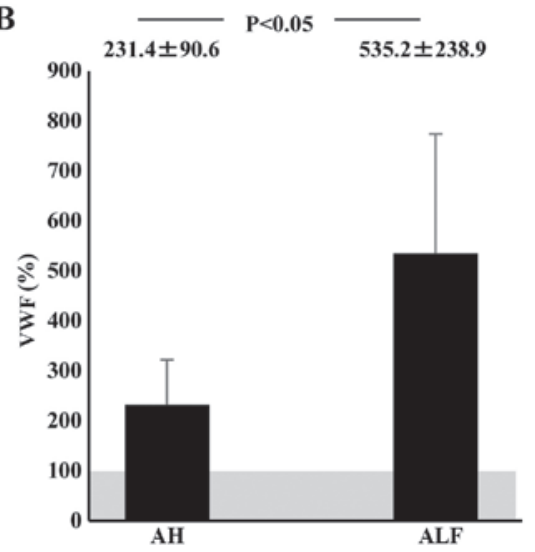

D

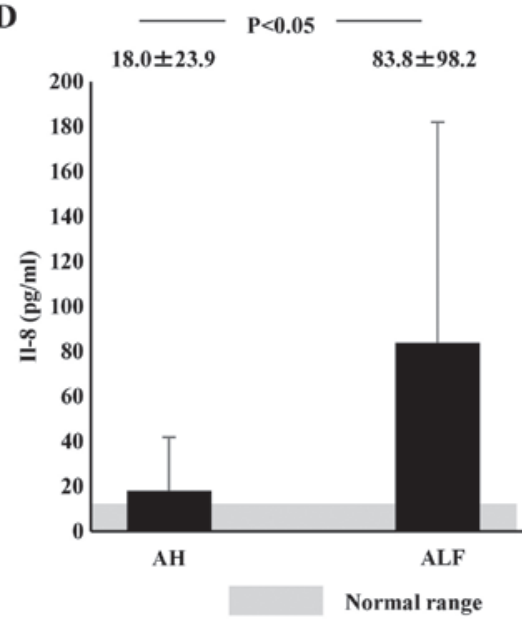

Figure 1. Plasma ADAMTS13:AC, VWF:Ag, and cytokine levels in AH or ALF patients on admission. Shaded area shows the normal range. (A) Plasma ADAMTS13:AC levels were significantly lower in ALF patients than in AH patients. (B) Plasma VWF:Ag levels were significantly higher in ALF patients than in AH patients. (C) IL-6 and (D) IL-8 concentrations were significantly higher in ALF patients than in AH patients. Data are expressed as means \pm standard deviation. $\mathrm{P}<0.05$ as indicated. ADAMTS13, ADAM metalloproteinase with thrombospondin type-1 motif, member 13; AC, activity; VWF, von Willebrand factor; Ag, antigen; AH, acute hepatitis; ALF, acute liver failure; IL, interleukin.
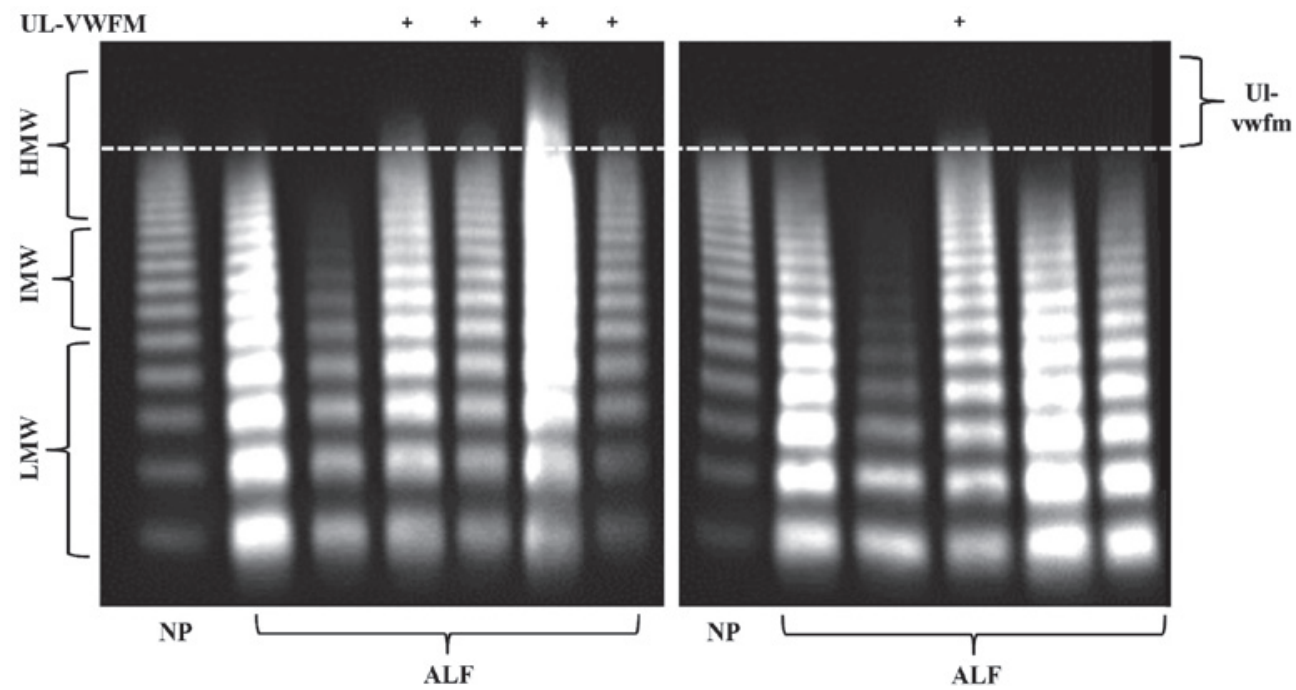

Figure 2. VWF multimers were classified as LMW (corresponding to bands $1-5$ in VWFM analysis), IMW (bands 6-10) and HMV (bands $\geq 11$ ). HMW bands that were not detected in normal plasma were defined as UL-VWFM. VWF, von Willebrand factor; LMW, low molecular weight; IMW, intermediate molecular weight; HMW, high molecular weight; UL-VWFM, unusually large von Willebrand factor multimers; ALF, acute liver failure; NP, normal plasma.

levels $\geq 20 \mathrm{pg} / \mathrm{ml}(437.6 \pm 418.8 \%)$ than in those with lower endotoxin levels (247.5.6 $\pm 109.4 \%$; $\mathrm{P}<0.05$; Fig. 5C).
Plasma ADAMTS13 inhibitor and its relationship to ADAMTS13:AC, VWF:Ag and clinical features. The plasma 
Table II. Changes in plasma ADAMTS13:AC and VWF:Ag in survivors and non-survivors with acute hepatitis and acute liver failure on admission.

\begin{tabular}{lccr}
\hline Variables & Survivors $(\mathrm{n}=29)$ & Non-survivors $(\mathrm{n}=9)$ & P-value \\
\hline ADAMTS13:AC (\%) & $53.9 \pm 34.6$ & $24.1 \pm 16.8$ & $\mathrm{P}<0.05$ \\
VWF:Ag (\%) & $252.8 \pm 127.4$ & $419.6 \pm 99.5$ & $\mathrm{P}<0.05$ \\
\hline
\end{tabular}

Data are expressed as means \pm standard deviation. ADAMTS13:AC, ADAM metalloproteinase with thrombospondin type-1 motif, member 13 activity; VWF:Ag, von Willebrand factor antigen.
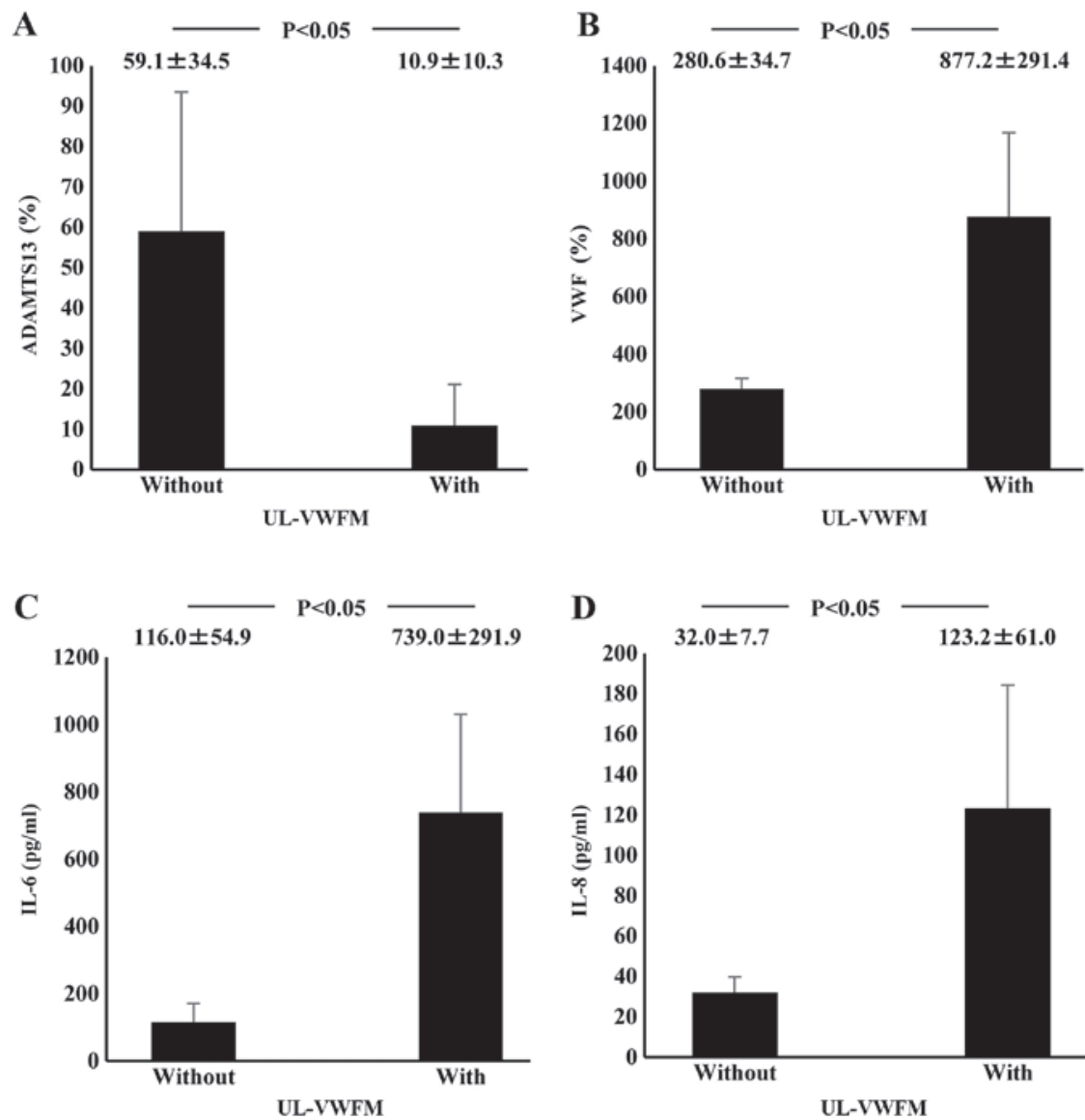

Figure 3. Relationship between plasma cytokine levels and UL-VWFM incidence in acute hepatitis and acute liver failure patients on admission. (A) Plasma ADAMTS13 activity values of patients with UL-VWFM were significantly lower than values of those without it. (B) Plasma VWF antigen values of patients with UL-VWFM were significantly higher than values of patients without it. (C) Plasma IL-6 levels of patients with UL-VWFM were significantly higher than levels of those without it. (D) Plasma IL-8 levels of patients with UL-VWFM were significantly higher than level of those without it. Data are expressed as means \pm standard deviation. P $<0.05$ as indicated. UL-VWFM, unusually large von Willebrand factor multimers; ADAMTS13, ADAM metalloproteinase with thrombospondin type-1 motif, member 13; IL, interleukin.

ADAMTS13 inhibitor was detected on admission in 8 ALF $(66.7 \%)$ and $6 \mathrm{AH}$ patients $(22.2 \%)$. The average inhibitory titer was $1.2 \mathrm{BU} / \mathrm{ml}$ (range, $0.6-2.4 \mathrm{BU} / \mathrm{ml}$ ) in ALF patients and $0.7 \mathrm{BU} / \mathrm{ml}$ (range, $0.6-0.8 \mathrm{BU} / \mathrm{ml}$ ) in AH patients. Patients with theinhibitor showed lowerADAMTS13:AC and higherVWF:Ag than those without the inhibitor (Fig. 6). AH and ALF patients who had the inhibitor presented lower levels of serum albumin $(3.2 \pm 0.6 \mathrm{~g} / \mathrm{dl}$ vs. $3.8 \pm 0.6 \mathrm{~g} / \mathrm{dl} ; \mathrm{P}<0.05)$ and higher levels of blood urea nitrogen $(35.8 \pm 36.2 \mathrm{~g} / \mathrm{dl}$ vs. $13.4 \pm 13.3 \mathrm{mg} / \mathrm{dl} ; \mathrm{P}<0.05)$, creatinine $(1.5 \pm 1.1 \mathrm{mg} / \mathrm{dl}$ vs. $0.8 \pm 0.5 \mathrm{mg} / \mathrm{dl} ; \mathrm{P}<0.05)$ and white blood cell count $(9,839.2 \pm 5,813.4 / \mu 1$ vs. $6,160.5 \pm 2,629.4 / \mu 1$; $\mathrm{P}<0.05)$.

\section{Discussion}

The authors reported that low ADAMTS13:AC and high VWF:Ag were closely related to plasma endotoxin, pro-inflammatory cytokines and poor prognosis in AH and ALF patients. Hugenholtz et al (9) reported low ADAMTS13:AC and high VWF:Ag in AH and ALF patients. However, they stated that low ADAMTS13:AC, but not high VWF:Ag, was associated with poor outcome. The reported lower ADAMTS13:AC and higher VWF:Ag, in ALF patients than in AH patients. A total of 9 of our 11 ALF patients died from hepatic failure within 12-132 days of admission. An analysis of the relationship of 

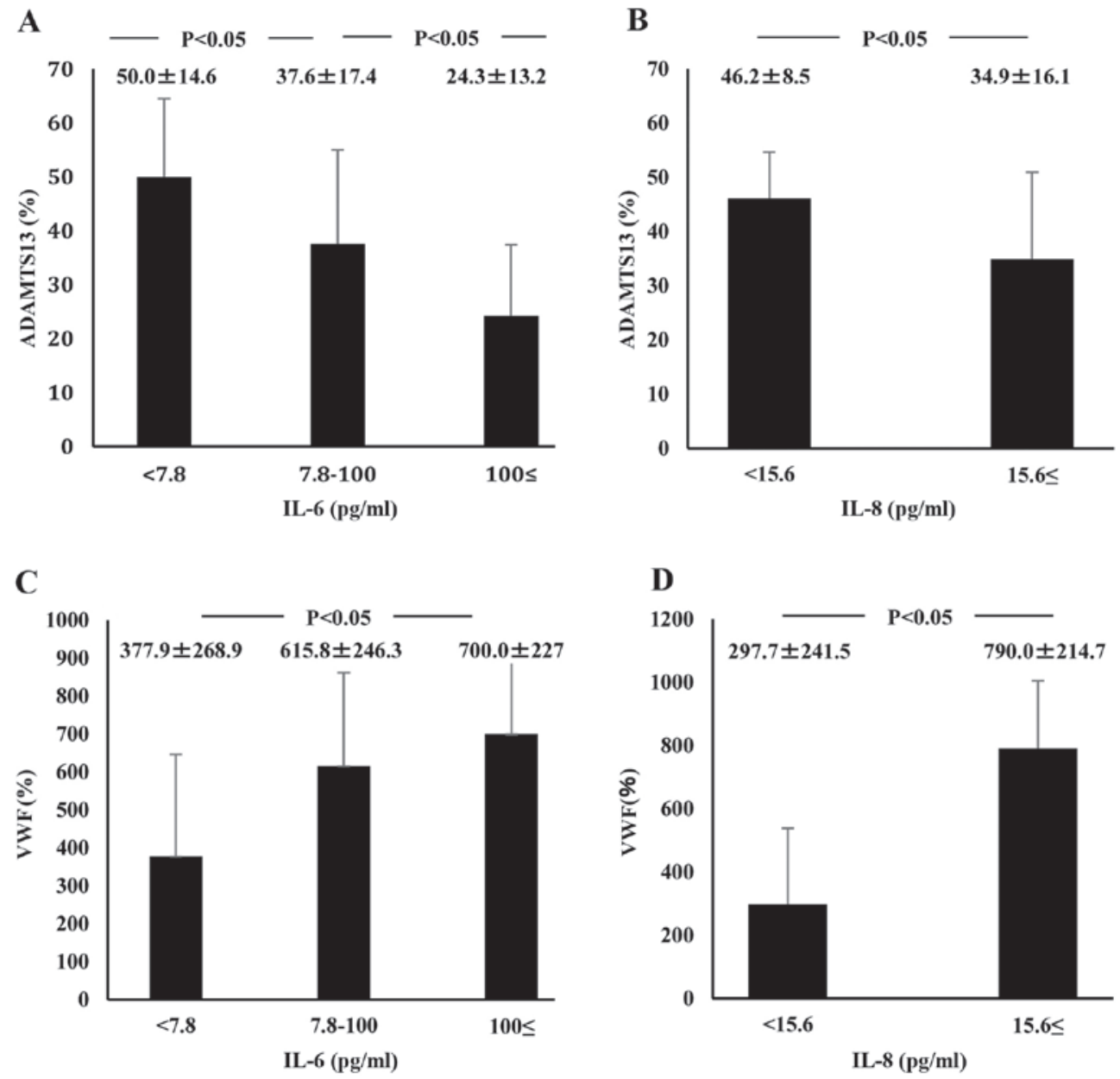

Figure 4. Relationship between plasma cytokine levels, ADAMTS13 activity, and VWF:Ag in AH and ALF patients on admission. IL-6 plasma level detection limit is below $7.8 \mathrm{pg} / \mathrm{ml}$ and that of IL-8 plasma level is below $15.6 \mathrm{pg} / \mathrm{ml}$. (A) ADAMTS13 activity concomitantly decreased with increasing IL-6 plasma levels. (B) Activity was lower in patients with IL-8 levels $\geq 15.6 \mathrm{pg} / \mathrm{ml}$ than in those with IL- $8<15.6 \mathrm{pg} / \mathrm{ml}$ levels. (C) VWF:Ag concomitantly increased with increasing plasma levels of IL-6. (D) In addition, the antigen increased in patients with IL-8 levels $\geq 15.6 \mathrm{pg} / \mathrm{ml}$ compared with those with IL-8 levels $<15.6 \mathrm{pg} / \mathrm{ml}$. Data are expressed as means \pm standard deviation. $\mathrm{P}<0.05$ as indicated. ADAMTS13, ADAM metalloproteinase with thrombospondin type-1 motif, member 13; VWF, von Willebrand factor; Ag, antigen; AH, acute hepatitis; ALF, acute liver failure; IL, interleukin.
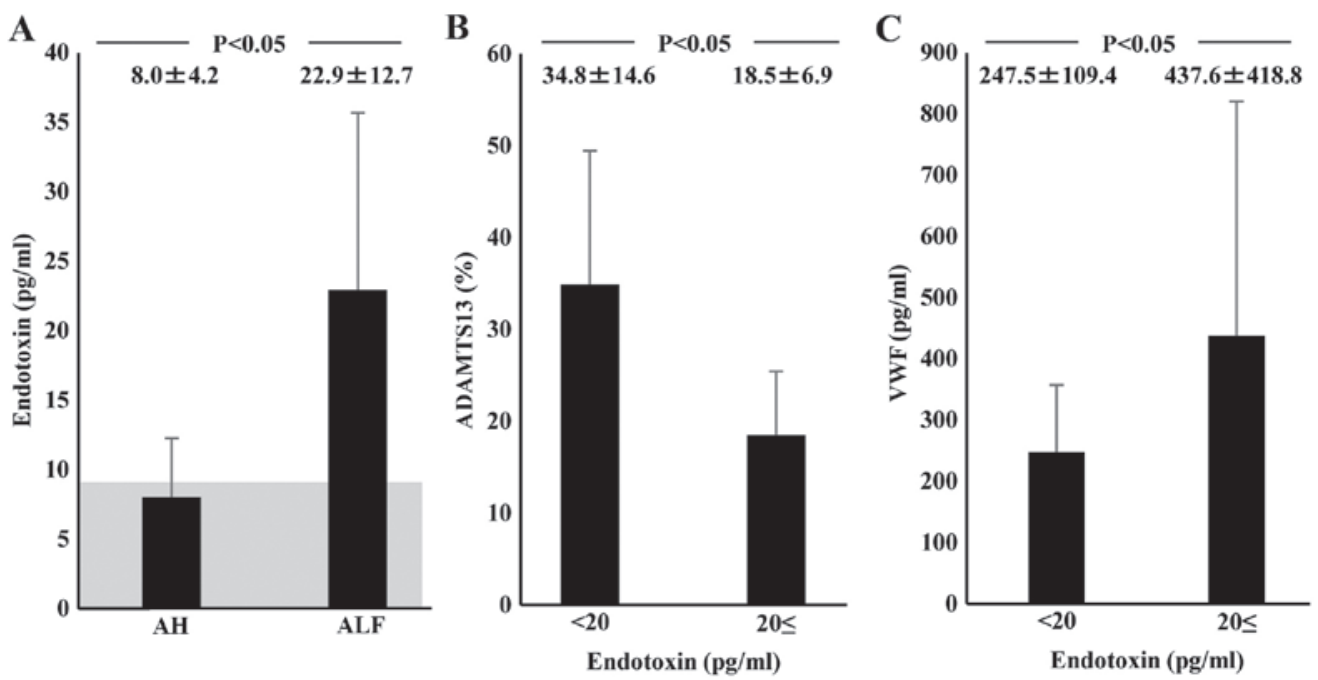

Normal range

Figure 5. Relationship of plasma endotoxin to ADAMTS13 activity and VWF:Ag in AH and ALF patients on admission. Shaded area shows the normal range. (A) Plasma endotoxin concentrations on admission were significantly higher in AH and ALF patients than in normal subjects; it was higher in ALF patients than in AH patients. (B) Patients with plasma endotoxin $\geq 20 \mathrm{pg} / \mathrm{ml}$ showed lower ADAMTS13 activity and (C) higher VWF:Ag than those with endotoxin $<20 \mathrm{pg} / \mathrm{ml}$. Data are expressed as means \pm standard deviation. P $<0.05$ as indicated. ADAMTS13, ADAM metalloproteinase with thrombospondin type-1 motif, member 13; VWF, von Willebrand factor; Ag, antigen; AH, acute hepatitis; ALF, acute liver failure. 
A

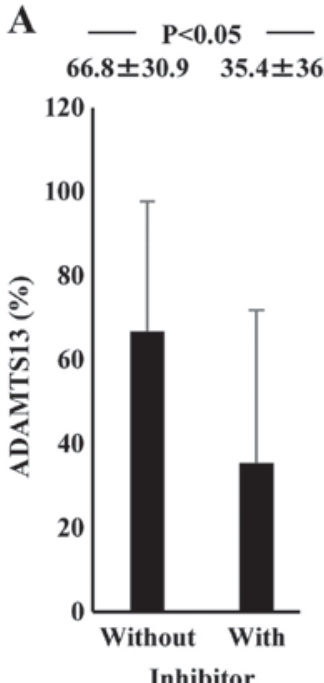

B

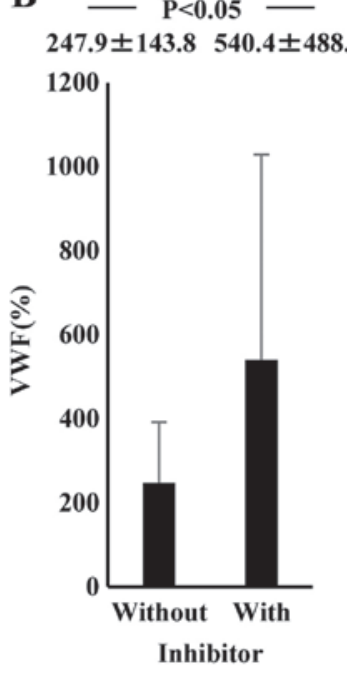

Figure 6. Relationship of plasma ADAMTS13 inhibitor to ADAMTS13:AC and VWF:Ag in $\mathrm{AH}$ and ALF patients on admission. Patients with the inhibitor reported (A) lower ADAMTS13:AC and (B) higher VWF:Ag than those without the inhibitor. Data are expressed as means \pm standard deviation. $\mathrm{P}<0.05$ as indicated. ADAMTS13:AC, ADAM metalloproteinase with thrombospondin type-1 motif, member 13 activity; VWF, von Willebrand factor; Ag, antigen; $\mathrm{AH}$, acute hepatitis; ALF, acute liver failure.

these parameters in all our subjects ( $\mathrm{AH}$ and $\mathrm{ALF}$ ) in relation to clinical course showed that ADAMTS13:AC and VWF:Ag changes were related to poor outcome and developing various complications. UL-VWFM was identified in 5 of $38 \mathrm{AH}$ and ALF patients who also had marked ADAMTS13:AC deficiency and marked high VWF values. These observations provide an explanation of the deleterious UL-VWFM effects on severe liver injury progression. Conversely, Hugenholtz et al (9) reported that UL-VWFM proportion was reduced in spite of markedly low ADAMTS13:AC in AH and ALF patients. They explained this discrepancy from the action of other proteases on VWF and/or the effect of treatment. They collected blood sample from the patients after starting the treatment. Thus, they did not analyze UL-VWFM on admission correctly but agreed to UL-VWFM effects on platelet thrombi formation in hepatic microvasculature and resultant tissue ischemia.

The dysfunctional ADAMTS13:AC and VWF:Ag mechanisms in hepatic failure remain unknown. Here, ADAMTS13:AC gradually decreased and VWF:Ag progressively increased with concomitant increases in IL-6 and IL-8 concentrations. Plasma IL-6 and IL-8 levels were significantly higher in patients with UL-VWFM than in those without it. It has been demonstrated in vitro with human umbilical vein endothelial cells that IL-6 inhibits the ADAMTS13 actions under flow conditions, while IL-8 stimulates UL-VWFM release (12).

ALF is characterized by massive necroinflammation of liver tissue and is associated with high mortality $(21,22)$. High serum proinflammatory cytokines levels have been reported $(21,22)$ and are related to the development of multiorgan dysfunction (23). Pro-inflammatory cytokines are also involved in the systemic inflammatory response syndrome pathophysiology (24). Pro-inflammatory cytokine removal is important during continuous hemodiafiltration for acute hepatic failure (25). Marked increases in pro-inflammatory cytokines
(IL-6 and IL-8) may have decreased ADAMTS13:AC and increased VWF:Ag, along with UL-VWFM, possibly leading to MOF development in ALF with through microcirculatory disturbances.

However, endotoxemia serves an important role in the initiation and aggravation of acute liver injury through the enhancement of proinflammatory cytokines, including IL-6 and IL-8 $(10,26)$. Here, pro-inflammatory cytokine (IL-6 and IL-8) concentrations and plasma endotoxin levels were significantly increased in ALF patients. The chromogenic endotoxin assay with kinetic analysis following plasma pretreatment with detergent (Triton X-100) and heating at $70^{\circ} \mathrm{C}$ for $10 \mathrm{~min}$ was based on the authors' previous basic experiments $(19,27)$. Compared with endotoxin levels $<20 \mathrm{pg} / \mathrm{ml}$, those $\geq 20 \mathrm{pg} / \mathrm{ml}$ were related to lower ADAMTS13:AC and higher VWF:Ag. These results indicated that enhanced endotoxemia may be closely related to decreased ADAMTS13:AC and increased VWF:Ag through enhanced cytokinemia.

To the best of the authors' knowledge, the present study is the first report to demonstrate a potential linkage between endotoxemia, enhanced inflammatory cytokines and the imbalance between decreased ADAMTS13:AC and increase in its substrate VWF:Ag, leading to systemic microcirculatory disturbances in ALF patients. A previous study (13) demonstrated that deficiency of ADAMTS13-associated inflammation promotes UL-VWFM the formation and severe, secondary ADAMTS13 deficiency can be associated with sepsis-induced DIC and may contribute to renal failure development (28), supporting the authors' data and hypothesis.

Likewise, another mechanism reducing ADAMTS13:AC is the presence of the plasma inhibitor against ADAMTS13. Here, the inhibitor was detected in $66.7 \%$ of ALF patients and in $22.2 \%$ of $\mathrm{AH}$ patients; inhibitory activity averaged 1.2 $\mathrm{BU} / \mathrm{ml}$ in ALF and $0.7 \mathrm{BU} / \mathrm{ml}$ in $\mathrm{AH}$. Patients with the inhibitor reported lower ADAMTS13:AC and higher VWF:Ag than those without the inhibitor. AH and ALF patients with the inhibitor presented higher blood urea nitrogen, serum creatinine and white blood cell counts, and lower serum albumin than those without the inhibitor, suggesting that decreased ADAMTS13:AC is caused by the presence of its inhibitor, closely related to lower functional liver capacity, marked inflammation and enhanced endotoxemia in ALF patients.

Clarifying what types of inhibitors may be involved in the association with inflammatory cytokines and endotoxin is necessary. The authors recently encountered two patients who developed TTP; one occurring during hepatitis $\mathrm{C}$ virus (HCV)-related advanced liver cirrhosis course (29) and the other occurring a month following pegylated-interferon $\alpha-2 \mathrm{a}$ therapy in a HCV-related chronic hepatitis patient (30). In both, plasma ADAMTS13:AC levels were extremely low; the inhibitor against ADAMTS13 was detected in each patient's heated plasma (2.0 and $1.6 \mathrm{BU} / \mathrm{ml}$, respectively) and purified $\operatorname{IgG}(0.19$ and $0.4 \mathrm{BU} / \mathrm{ml} \mathrm{IgG}$, respectively). The authors of a previous study detected IgG-inhibitor using western blotting in four patients with advanced liver cirrhosis and extremely low ADAMTS13:AC ( $<3 \%$ controls) without clinical TTP features (8). Some end-stage cirrhotic patients have extremely low ADAMTS13:AC with the IgG-inhibitor against ADAMTS13, similar to TTP patients. However, rapid IgG-inhibitor development following ALF 
onset is unknown. Intravenous endotoxin infusion in healthy volunteers decreased plasma ADAMTS13:AC and increased VWF:Ag and UL-VWFM during acute systemic inflammation (31). These results and those of others indicated that endotoxemia may reduce plasma ADAMTS13:AC, or together with inflammatory cytokines, in patients with ALF. Further studies are warranted to clarify the kind of inhibitors, other than the IgG-inhibitor, involved in AHF patients with lower ADAMTS13:AC.

Therefore, enhanced cytokinemia and ADAMTS13:AC inhibitor, closely related to enhanced endotoxemia in ALF patients, decreased ADAMTS13:AC and increased VWF:Ag. Cytokinemia and inhibitor presence cause an enzyme-substrate imbalance, resulting in MOF, particularly in ALF patients. Regarding mechanism of ADAMTS13 depletion, further experimental studies are required. The presented results raise the possibility of novel supportive therapies for ALF patients, including ADAMTS13 supplementation or anti-inflammatory cytokine agents.

\section{Acknowledgements}

The present study was completed with the great help of the late Professor Masahito Uemura. The authors would like to thank Ayami Isonishi for her great help in the assay of ADAMTS13:AC and VWF:Ag. The study was supported in part by research grants (grant no. 20590794) from the Ministry of Education, Culture, Sports, Science and Technology of Japan.

\section{References}

1. Zheng X, Chung D, Takayama TK, Majerus EM, Sadler JE and Fujikawa K: Structure of von Willebrand factor-cleaving protease (ADAMTS13), a metalloprotease involved in thrombotic thrombocytopenic purpura. J Biol Chem 276: 41059-41063, 2001.

2. Uemura M, Tatsumi K, Matsumoto M, Fujimoto M, Matsuyama T, Ishikawa M, Iwamoto TA, Mori T, Wanaka A, Fukui $\mathrm{H}$ and Fujimura Y: Localization of ADAMTS13 to the stellate cells of human liver. Blood 106: 922-924, 2005.

3. Moake JL, Turner NA, Stathopoulos NA, Nolasco LH and Hellums JD: Involvement of large plasma von Willebrand factor (vWF) multimers and unusually large vWF forms derived from endothelial cells in shear stress-induced platelet aggregation. J Clin Invest 78: 1456-1461, 1986.

4. Levy GG, Nichols WC, Lian EC, Foroud T, McClintick JN, McGee BM, Yang AY, Siemieniak DR, Stark KR, Gruppo R, et al: Mutations in a member of the ADAMTS gene family cause thrombotic thrombocytopenic purpura. Nature 413: 488-494, 2001.

5. Furlan M, Robles R, Galbusera M, Remuzzi G, Kyrle PA, Brenner B, Krause M, Scharrer I, Aumann V, Mittler U, et al: von Willebrand factor-cleaving protease in thrombotic thrombocytopenic purpura and the hemolytic-uremic syndrome. N Engl J Med 339: 1578-1584, 1998

6. Griffin D, Al-Nouri ZL, Muthurajah D, Ross JR, Ballard RB, Terrell DR, Vesely SK, George JN and Marques MB: First symptoms in patients with thrombotic thrombocytopenic purpura: What are they and when do they occur? Transfusion 53: 235-237, 2013.

7. Ishikawa M, Uemura M, Matsuyama T, Matsumoto M, Ishizashi $\mathrm{H}$, Kato S, Morioka C, Fujimoto M, Kojima H, Yoshiji H, et al: Potential role of enhanced cytokinemia and plasma inhibitor on the decreased activity of plasma ADAMTS13 in patients with alcoholic hepatitis: relationship to endotoxemia. Alcohol Clin Exp Res 34 (Suppl 1): 25-33, 2010.

8. Uemura M, Fujimura Y, Matsumoto M, Ishizashi H, Kato S, Matsuyama T, Isonishi A, Ishikawa M, Yagita M, Morioka C, et al: Comprehensive analysis of ADAMTS13 in patients with liver cirrhosis. Thromb Haemost 99: 1019-1029, 2008.
9. Hugenholtz GC, Adelmeijer J, Meijers JC, Porte RJ, Stravitz RT and Lisman T: An unbalance between von Willebrand factor and ADAMTS13 in acute liver failure: Implications for hemostasis and clinical outcome. Hepatology 58: 752-761, 2013.

10. Fukui H: Relation of endotoxin, endotoxin binding proteins and macrophages to severe alcoholic liver injury and multiple organ failure. Alcohol Clin Exp Res 29: 172S-179S, 2005.

11. Nolan JP: The role of intestinal endotoxin in liver injury: A long and evolving history. Hepatology 52: 1829-1835, 2010.

12. Cao WJ, Niiya M, Zheng XW, Shang DZ and Zheng XL: Inflammatory cytokines inhibit ADAMTS13 synthesis in hepatic stellate cells and endothelial cells. J Thromb Haemost 6: 1233-1235, 2008.

13. Bernardo A, Ball C, Nolasco L, Moake JF and Dong JF: Effects of inflammatory cytokines on the release and cleavage of the endothelial cell-derived ultralarge von Willebrand factor multimers under flow. Blood 104: 100-106, 2004.

14. Bockmeyer CL, Claus RA, Budde U, Kentouche K, Schneppenheim R, Lösche W, Reinhart K and Brunkhorst FM: Inflammation-associated ADAMTS13 deficiency promotes formation of ultra-large von Willebrand factor. Haematologica 93: 137-140, 2008.

15. Mochida S, Nakayama N, Ido A, Takikawa Y, Yokosuka O, Sakaida I, Moriwaki H, Genda T and Takikawa H: Revised criteria for classification of the etiologies of acute liver failure and late-onset hepatic failure in Japan: A report by the Intractable Hepato-biliary Diseases Study Group of Japan in 2015. Hepatol Res 46: 369-371, 2016

16. Matsumoto M, Kawa K, Uemura M,Kato S, IshizashiH, Isonishi A, Yagi H, Park YD, Takeshima Y, Kosaka Y, et al: Prophylactic fresh frozen plasma may prevent development of hepatic VOD after stem cell transplantation via ADAMTS13-mediated restoration of von Willebrand factor plasma levels. Bone Marrow Transplant 40: 251-259, 2007.

17. Koyama N, Matsumoto M, Tamaki S, Yoshikawa M, Fujimura Y and Kimura H: Reduced larger von Willebrand factor multimers at dawn in OSA plasmas reflect severity of apnoeic episodes. Eur Respir J 40: 657-664, 2012.

18. Kasper CK, Aledort L, Aronson D, Counts R, Edson JR, van Eys J, Fratantoni J, Green D, Hampton J, Hilgartner M, et al: Proceedings: A more uniform measurement of factor VIII inhibitors. Thromb Diath Haemorrh 34: 612, 1975.

19. Fukui H, Brauner B, Bode JC and Bode C: Plasma endotoxin concentrations in patients with alcoholic and non-alcoholic liver disease: Reevaluation with an improved chromogenic assay. J Hepatol 12: 162-169, 1991.

20. Kanda Y: Investigation of the freely available easy-to-use software 'EZR' for medical statistics. Bone Marrow Transplant 48: 452-458, 2013.

21. Shah N, Montes de Oca M, Jover-Cobos M, Tanamoto K, Muroi M, Sugiyama K, Davies NA, Mookerjee RP, Dhar DK and Jalan R: Role of toll-like receptor 4 in mediating multiorgan dysfunction in mice with acetaminophen induced acute liver failure. Liver Transpl 19: 751-761, 2013.

22. Melgaço JG, Soriani FM, Sucupira PH, Pinheiro LA, Vieira YR, de Oliveira JM, Lewis-Ximenez LL, Araújo CC, PachecoMoreira LF, Menezes GB, et al: Changes in cellular proliferation and plasma products are associated with liver failure. World $\mathbf{J}$ Hepatol 8: 1370-1383, 2016.

23. Mookerjee RP, Dalton RN, Davies NA, Hodges SJ, Turner C, Williams R and Jalan R: Inflammation is an important determinant of levels of the endogenous nitric oxide synthase inhibitor asymmetric dimethylarginine (ADMA) in acute liver failure. Liver Transpl 13: 400-405, 2007.

24. Rolando N, Wade J, Davalos M, Wendon J, Philpott-Howard J and Williams R: The systemic inflammatory response syndrome in acute liver failure. Hepatology 32: 734-739, 2000.

25. Shinozaki K, Oda S, Abe R, Tateishi Y, Yokoi T and Hirasawa H: Blood purification in fulminant hepatic failure. Contrib Nephrol 166: 64-72, 2010.

26. Fujimoto M, Uemura M, Nakatani Y, Tsujita S, Hoppo K, Tamagawa T, Kitano H, Kikukawa M, Ann T, Ishii Y, et al: Plasma endotoxin and serum cytokine levels in patients with alcoholic hepatitis: Relation to severity of liver disturbance. Alcohol Clin Exp Res 24 (Suppl): 48S-54S, 2000.

27. Fukui H, Brauner B, Bode JC and Bode C: Chromogenic endotoxin assay in plasma. Selection of plasma pretreatment and production of standard curves. J Clin Chem Clin Biochem 27: 941-946, 1989. 
28. Ono T, Mimuro J, Madoiwa S, Soejima K, Kashiwakura Y, Ishiwata A, Takano K, Ohmori T and Sakata Y: Severe secondary deficiency of von Willebrand factor-cleaving protease (ADAMTS13) in patients with sepsis-induced disseminated intravascular coagulation: Its correlation with development of renal failure. Blood 107: 528-534, 2006.

29. Yagita M, Uemura M, Nakamura T, Kunitomi A, Matsumoto M and Fujimura Y: Development of ADAMTS13 inhibitor in a patient with hepatitis $\mathrm{C}$ virus-related liver cirrhosis causes thrombotic thrombocytopenic purpura. J Hepatol 42: 420-421, 2005.
30. Kitano K, Gibo Y, Kamijo A, Furuta K, Oguchi S, Joshita S, Takahashi Y, Ishida F, Matsumoto M, Uemura M and Fujimura Y: Thrombotic thrombocytopenic purpura associated with pegylated-interferon alpha-2a by an ADAMTS13 inhibitor in a patient with chronic hepatitis C. Haematologica 91: ECR34, 2006.

31. Reiter RA, Varadi K, Turecek PL, Jilma B and Knöbl P: Changes in ADAMTS13 (von-Willebrand-factor-cleaving protease) activity after induced release of von Willebrand factor during acute systemic inflammation. Thromb Haemost 93: 554-558, 2005. 